\title{
Secondary structure-driven self-assembly of thiol-reactive polypept(o)ides
}

Bauer, T. A.; Imschweiler, J.; Muhl, C.; Weber, B.; Barz, M.

\section{Citation}

Bauer, T. A., Imschweiler, J., Muhl, C., Weber, B., \& Barz, M. (2021). Secondary structure-driven self-assembly of thiol-reactive polypept(o)ides. Biomacromolecules, 22(5), 2171-2180.

doi:10.1021/acs.biomac.1c00253

Version: $\quad$ Publisher's Version

License: $\quad$ Creative Commons CC BY-NC-ND 4.0 license

Downloaded from: https://hdl.handle.net/1887/3216827

Note: To cite this publication please use the final published version (if applicable). 


\title{
Secondary Structure-Driven Self-Assembly of Thiol-Reactive Polypept(o)ides
}

\author{
Tobias A. Bauer, Jan Imschweiler, Christian Muhl, Benjamin Weber, and Matthias Barz*
}

Cite This: Biomacromolecules 2021, 22, 2171-2180

Read Online

ABSTRACT: Secondary structure formation differentiates polypeptides from most of the other synthetic polymers, and the transitions from random coils to rod-like $\alpha$-helices or $\beta$-sheets represent an additional parameter to direct self-assembly and the morphology of nanostructures. We investigated the influence of distinct secondary structures on the self-assembly of reactive amphiphilic polypept(o)ides. The individual morphologies can be preserved by core cross-linking via chemoselective disulfide bond formation. A series of thiol-responsive copolymers of racemic polysarcosine-block-poly (S-ethylsulfonyl-DL-cysteine) (pSar-b-p(DL)Cys), enantiopure polysarcosine-block-poly(S-ethylsulfonyl-L-

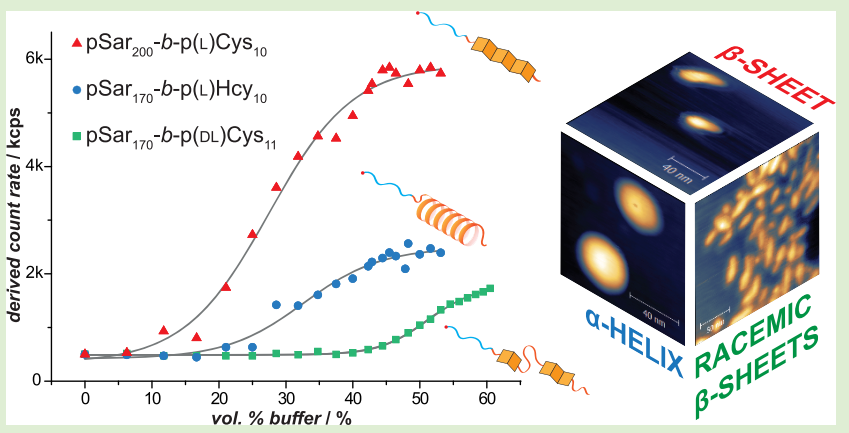
cysteine) (pSar- $b$-p(L)Cys), and polysarcosine-block-poly $(S$-ethylsulfonyl-L-homocysteine) (pSar-b-p(L)Hcy) was prepared by $N$-carboxyanhydride polymerization. The secondary structure of the peptide segment varies from $\alpha$-helices (pSar- $b$ - $\mathrm{p}(\mathrm{L}) \mathrm{Hcy}$ ) to antiparallel $\beta$-sheets (pSar- $b$ - $\mathrm{p}(\mathrm{L})$ Cys) and disrupted $\beta$-sheets (pSar- $b$ $\mathrm{p}(\mathrm{DL}) \mathrm{Cys})$. When subjected to nanoprecipitation, copolymers with antiparallel $\beta$-sheets display the strongest tendency to selfassemble, whereas disrupted $\beta$-sheets hardly induce aggregation. This translates to worm-like micelles, solely spherical micelles, or ellipsoidal structures, as analyzed by atomic force microscopy and cryogenic transmission electron microscopy, which underlines the potential of secondary structure-driven self-assembly of synthetic polypeptides.

\section{INTRODUCTION}

Secondary structure formation as a feature of polypeptides is the fundamental basis for the higher ordered structural diversity and specific function of proteins and other biomaterials. $^{1-3}$ As a prominent example, the polyalanine domains of spider silk undergo a transition from $\alpha$-helices in solution to highly ordered $\beta$-sheets in the solid state, which, among other factors, accounts for feasible processing paired with exceptional elasticity and toughness. ${ }^{4-7}$ Consequently, not only from a polymer chemistry perspective, secondary structure displays an additional parameter influencing the preparation and application of peptide materials. ${ }^{8-11}$ For polypeptides derived from single amino acids, primarily, $\alpha$ helices or $\beta$-sheets are obtained, with exceptions for prolinetype amino acids. ${ }^{1,12}$ Upon secondary structure formation, the induced coil-to-helix or coil-to-sheet transitions refer to a rigidification of the polymer segment (rod-like structures) and provide a driving force for self-assembly. ${ }^{1,13}$ In particular for synthetic polypeptides of polyglutamic acid and polylysine, the stimuli that induce $\alpha$-helix formation, such as $\mathrm{pH}$ or temperature, have been the subject of multiple investigations. ${ }^{14-20}$ Furthermore, Deming and co-workers intensively elucidated the thermo- and redox-responsiveness of $\alpha$-helical polyhomocysteine derivatives. ${ }^{21,22}$ On the other hand, for polyserine or polycysteine, research has been more dedicated to resolving the strong induction of $\beta$-sheet formation, e.g., by side chain functionalization with oligo ethylene glycol moieties. $^{23-25}$

In contrast to polypeptides, polypeptoids, with the branching on the nitrogen atom instead of the $\alpha$-position, do not show classical secondary structure formation as no hydrogen bond donor is present if no specific modification was introduced. ${ }^{26-28}$ As such, polysarcosine ( $\mathrm{pSar}$, poly $(\mathrm{N}$ methyl glycine)) adopts random coil conformation in aqueous solution, is highly water-soluble (A2 parameter of $3.50 \cdot 10^{-6}$ $\mathrm{mol} \cdot \mathrm{dm}^{3} \cdot \mathrm{g}^{-2}$ for $\mathrm{pSar}_{185}$ at $\left.20{ }^{\circ} \mathrm{C}\right)$, and can be considered a stealth-like material. ${ }^{29-33}$ For medical applications, polysarcosine is considered the most promising alternative to polyethylene glycol since substantial advantages like reduced proinflammatory cytokine secretion and reduced complement activation as well as evasion of the accelerated blood clearance $(\mathrm{ABC})$ phenomenon have been reported. ${ }^{30,33-35}$ The combination of polypeptides and polysarcosine in polypept(o)ides thus represent a promising class of biobased or even

Received: February 25, 2021

Revised: March 25, 2021

Published: April 8, 2021

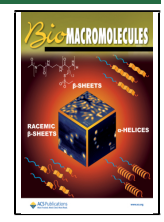


endogenous materials. ${ }^{26,36,37}$ While the concept of polypept(o)ides extends from linear block copolymers to cylindrical bottle-brush and star-shaped polymers including miktoarm stars, ${ }^{36,38-40}$ polysarcosine itself has further been successfully combined with various other classes of synthetic polymers. $^{37,41,42}$

With its ability to form bioreversible disulfide bonds, the non-essential amino acid cysteine plays a unique role within nature. ${ }^{43,44}$ In living cells, catalyzing proteins and small molecules orchestrate disulfide bond formation among specific cysteines generating functional proteins. ${ }^{45}$ To transfer chemoselective disulfide bond formation to functional polymers, our group reported on the reactive $S$-alkylsulfonyl-protecting group for cysteine and homocysteine. ${ }^{46,47}$ This reactive group differentiates hard and soft nucleophiles and grants living amine-initiated ring-opening polymerization of $S$-alkylsulfonylprotected $\mathrm{N}$-carboxyanhydrides (NCAs). The $S$-alkylsulfonyl group can then be addressed by post polymerization modification reactions with soft nucleophiles, e.g., thiols, for disulfide bond formation. With respect to secondary structure, homopolypeptides of $S$-ethylsulfonyl-L-cysteine $(\mathrm{p}(\mathrm{L}) \mathrm{Cys})$ were shown to adopt antiparallel $\beta$-sheets, while $\beta$-sheets were even detected for the racemic mixture, poly $(S$-ethylsulfonyl-DL-cysteine) ( $\mathrm{p}(\mathrm{DL}) \mathrm{Cys})$, albeit to a much lesser extent. $^{47,48}$ In contrast, poly( $S$-ethylsulfonyl-L-homocysteine) ( $\mathrm{p}(\mathrm{L}) \mathrm{Hcy})$, which has only one additional methylene group in the side chain as compared to the parent cysteine, was shown to adopt an $\alpha$-helical structure in solution and solid state. ${ }^{49}$

Since antiparallel $\beta$-sheets of enantiopure polysarcosineblock-poly(S-ethylsulfonyl-L-cysteine) (pSar-b-p(L)Cys) were shown to direct self-assembly to worm-like micelles previously, ${ }^{50}$ we now contribute a comprehensive study on the influence of the secondary structure on the self-assembly of reactive block copolypept(o)ides. Therefore, $S$-ethylsulfonylprotected reactive copolymers with varying secondary structures ( $\alpha$-helices, antiparallel $\beta$-sheets, and disrupted $\beta$ sheets) have been synthesized by ring-opening NCA polymerization, and their aggregation behavior was analyzed by DLS, AFM, and cryoTEM.

\section{MATERIALS AND METHODS}

Unless stated otherwise, reagents and solvents were purchased from Sigma-Aldrich and used as received. N,N-Dimethylformamide (DMF) was bought from Acros (99.8\%, extra dry over molecular sieves) and purified by repetitive freeze-pump thaw cycles prior to use (water content, $<50 \mathrm{ppm}$ ). $N$-tert-Butoxycarbonyl (Boc)-1,2-diaminoethane was obtained from Sigma-Aldrich $(\geq 98 \%)$ and stored over activated molecular sieves before further use. Milli- $\mathrm{Q}$ water was prepared using a MILLI-Q Reference A+ system. Water was used at a resistivity of 18.2 M $\Omega \cdot \mathrm{cm}^{-1}$ and a total organic carbon (TOC) of $<5 \mathrm{ppm}$. Hexafluoroisopropanol (HFIP) and potassium trifluoroacetate were purchased from Fluorochem. Deuterated solvents were obtained from Deutero $\mathrm{GmbH}$ and were used as received.

${ }^{1} \mathrm{H}$ NMR spectra were recorded on a Bruker Avance II 400 at room temperature at a frequency of $400 \mathrm{MHz}$. DOSY spectra were recorded on a Bruker Avance III HD $400(400 \mathrm{MHz})$. Calibration of the spectra was achieved using the solvent signals. NMR spectra were analyzed with MestReNova version 12.0.4 from Mestrelab Research S.L. Degrees of polymerization $\left(X_{n}\right)$ by ${ }^{1} \mathrm{H}$ NMR were calculated by comparing the integral of the initiator peak and the integrals of the $\alpha$ protons. For block copolymers containing polysarcosine, the chain lengths of the second block were calculated from the integral of the $\alpha$ protons and the signals of the polysarcosine backbone, as derived from HFIP GPC relative to polysarcosine standards.
Attenuated total reflectance Fourier transform infrared (ATR-FTIR) spectroscopy was performed on a FT/IR-4100 (JASCO Corporation) with an ATR sampling accessory (MIRacle, Pike Technologies). IR spectra were analyzed using Spectra Manager 2.0 (JASCO Corporation). NCA polymerization was monitored by FT-IR spectroscopy, and the polymerization was judged to be completed if the carbonyl peaks at 1858 and $1788 \mathrm{~cm}^{-1}$ had vanished.

Analytical gel permeation chromatography (GPC) was performed on a Jasco GPC setup at a flow rate of $0.8 \mathrm{~mL} \cdot \mathrm{min}^{-1}$ and a temperature of $40{ }^{\circ} \mathrm{C}$. The eluent was HFIP equipped with $3 \mathrm{~g} \cdot \mathrm{L}^{-1}$ potassium trifluoroacetate. The column material was a modified silica gel (PFG columns; particle size, $7 \mu \mathrm{m}$; porosity, 100 and $4000 \AA$ ), purchased from PSS Polymer Standards Service GmbH. For polymer detection, a UV detector (Jasco UV-2075+) at a wavelength of $\lambda=$ $230 \mathrm{~nm}$ was employed. Molecular weights were determined by using a calibration with PMMA (PSS Polymer Standards Services GmbH) with toluene as an internal standard. The elution diagram was evaluated with PSS WinGPC (PSS Polymer Standards Service $\mathrm{GmbH})$.

Single-angle dynamic light scattering (DLS) measurements were performed with a ZetaSizer Nano ZS (Malvern Instruments, Ltd., Worcestershire, UK) equipped with a $\mathrm{He}-\mathrm{Ne}$ laser $(\lambda=632.8 \mathrm{~nm})$. All measurements were performed at $25{ }^{\circ} \mathrm{C}$ and a detection angle of $173^{\circ}$. Disposable polystyrene and organic solvent-resistant cuvettes (VWR, Darmstadt, Germany) were used for single-angle DLS measurements. The cumulant size, polydispersity index (PDI), size distribution (intensity weighted) histograms, and the derived count rate were calculated based on the autocorrelation function of the samples, with automated position and attenuator adjustment at multiple scans.

Circular dichroism (CD) spectroscopy was performed on a Jasco J815 spectrometer at a temperature of $20{ }^{\circ} \mathrm{C}$ using Spectra Manager 1.53.04 (Jasco). The spectra were recorded in HFIP at a concentration of $0.1 \mathrm{~g} \cdot \mathrm{L}^{-1}$ using a quartz cell with a path length of $1 \mathrm{~mm}$. $\theta_{\mathrm{MR}}$ was calculated with the equation below with $c_{\mathrm{M}}=0.1 \mathrm{~g}$. $\mathrm{L}^{-1}, l=0.1 \mathrm{~cm}$, and $M_{\text {Repeating Unit }}=195.26 \mathrm{~g} \cdot \mathrm{mol}^{-1}$ for $S$-ethylsulfonylL-cysteine and $S$-ethylsulfonyl-DL-cysteine, $M_{\text {Repeating Unit }}=209.26 \mathrm{~g}$. $\mathrm{mol}^{-1}$ for $S$-ethylsulfonyl-L-homocysteine, and $M_{\text {Repeating Unit }}=71.08 \mathrm{~g}$. $\mathrm{mol}^{-1}$ for sarcosine.

$$
\theta_{\mathrm{MR}}=\frac{\theta \cdot M_{\text {Repeating Unit }}}{10 \cdot c_{\mathrm{M}} \cdot l}\left[\mathrm{deg} \cdot \mathrm{cm}^{2} \cdot \mathrm{dmol}^{-1}\right]
$$

Atomic force microscopy (AFM) was measured on mica using a Cypher AFM (Asylum Research) using tapping mode at a scan rate of $1 \mathrm{~Hz}$. Samples were prepared by drop-casting of a particle solution $(V$ $=5 \mu \mathrm{L}$ and $\beta=50 \mathrm{mg} \cdot \mathrm{L}^{-1}$ in Milli-Q water) onto freshly cleaned mica. The sample was dried overnight at room temperature. Images were evaluated using Gwyddion 2.49.

For cryogenic transmission electron microscopy (CryoTEM), $5 \mu \mathrm{L}$ of CCPM solution ( $50 \mathrm{mg} \cdot \mathrm{L}^{-1}$, in Milli-Q water) was applied to freshly glow-discharged carbon grids with a copper 200 mesh (Quantifoil Micro Tools GmbH). The excess fluid was removed by direct blotting $(2.5 \mathrm{~s})$, and the grids were individually plunge-frozen in liquid ethane. Grids were cryotransferred in liquid nitrogen using a Gatan cryoholder (model $626 \mathrm{DH}$ ) to a Tecnai T12 transmission electron microscope equipped with a field emission electron source and operating at $120 \mathrm{kV}$ accelerating voltage. Images were recorded using a TemCam-F416 (TVIPS, Gauting, Germany). Software ImageJ $1.52 \mathrm{~h}$ (National Institutes of Health, USA) was used for image evaluation.

Polymer Synthesis. Polymers were prepared by amine-initiated ring-opening $\mathrm{N}$-carboxyanhydride (NCA) polymerization in dry DMF under Schlenk conditions. The respective monomers, sarcosine-NCA, $S$-ethylsulfonyl-DL-cysteine-NCA, S-ethylsulfonyl-L-cysteine-NCA, and $S$-ethylsulfonyl-L-homocysteine-NCA, were synthesized and characterized as reported previously. ${ }^{46,48,49}$

Polysarcosine ( pSar $_{n}$ ) (P1 and P2). Sarcosine-NCA ( 5.98 g, 52.0 mmol, and 200 equiv) was transferred into a predried Schlenk tube and dissolved in $60 \mathrm{~mL}$ of dry DMF, and $\mathrm{N}$-(tert-butoxycarbonyl)-1,2- 
Scheme 1. Synthesis of Block Copolypept(o)ides with Varying Secondary Structures

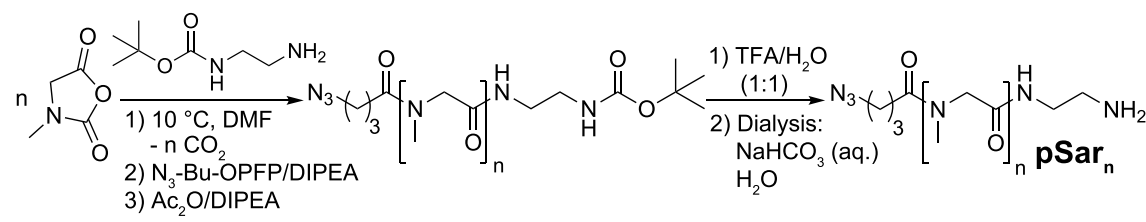
3) $\mathrm{AC}_{2} \mathrm{O} / \mathrm{DIPEA}$

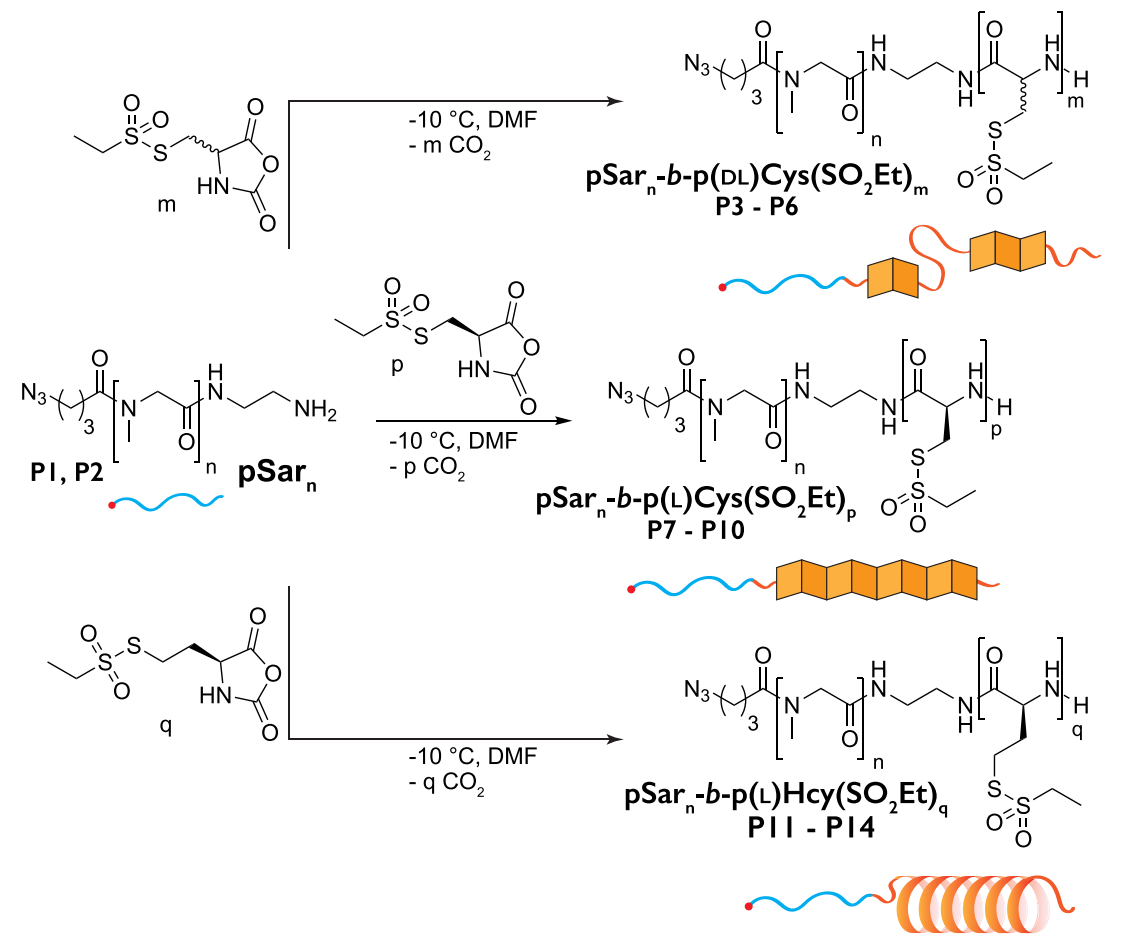

diaminoethane ( $41.6 \mathrm{mg}, 0.26 \mathrm{mmol}$, and 1.0 equiv) was added as a stock solution in dry DMF. The clear, colorless solution was stirred at $10^{\circ} \mathrm{C}$ in the absence of light until the reaction was completed after six days, as monitored by IR spectroscopy. The sarcosine amino terminus was quenched by addition perfluorophenyl-4-azidobutanoate (153 $\mathrm{mg}, 0.52 \mathrm{mmol}$, and 2.0 equiv) and $\mathrm{N}, \mathrm{N}$-diisopropylethylamine (221 $\mu \mathrm{L}, 1.30 \mathrm{mmol}$, and 5.0 equiv). The reaction mixture was stirred overnight followed by addition of acetic anhydride $(248 \mu \mathrm{L}, 2.60$ $\mathrm{mmol}$, and 10 equiv) and $N, N$-diisopropylethylamine $(884 \mu \mathrm{L}, 5.20$ $\mathrm{mmol}$, and 20 equiv) to react with residual end groups. The slightly yellow solution was stirred for one additional day at room temperature before the polymer was precipitated in $600 \mathrm{~mL}$ of diethyl ether, collected on a Buchner funnel, washed with acetone and diethyl ether, and dried in vacuo. Next, the Boc-protecting group was removed. The polymer $(3.4 \mathrm{~g})$ was dissolved in $50 \mathrm{~mL}$ of water and cooled to $0{ }^{\circ} \mathrm{C}$, and $50 \mathrm{~mL}$ of trifluoroacetic acid was added in one portion. After $4 \mathrm{~h}$ at $0{ }^{\circ} \mathrm{C}$, the solution was transferred into dialysis bags (MWCO, $3.5 \mathrm{kDa}$ ) and dialyzed against Milli- $\mathrm{Q}$ water, saturated sodium hydrogen carbonate solution, and Milli- $\mathrm{Q}$ water. The aqueous solution was lyophilized, and the polysarcosine (P1) was obtained as a colorless powder $(3.08 \mathrm{~g}, 82 \%) .{ }^{1} \mathrm{H}$ NMR $\left(400 \mathrm{MHz}, \mathrm{DMSO}-d_{6}\right): \delta$ (ppm) $4.50-3.76\left(\mathrm{~m}, 2 \mathrm{nH},-\mathrm{CH}_{2}-\right), 3.06-2.76\left(\mathrm{~m}, 3 \mathrm{nH},-\mathrm{CH}_{3}\right)$. The chain length was determined by HFIP GPC relative to polysarcosine standards. ${ }^{29}$

Block Copolymer Syntheses. All block copolymers were prepared from pSar macroinitiators, following the procedure described below for $\mathrm{pSar}-b-\mathrm{p}$ (DL)Cys using the respective NCAs. ${ }^{50}$

Polysarcosine $_{n}$-block-poly(S-ethylsulfonyl-DL-cysteine $)_{m}$ $\left(\mathrm{pSar}_{n}-\boldsymbol{b}-\mathrm{p}(\mathrm{DL}) \mathrm{Cys}_{m}\right) \quad(\mathrm{P3}-\mathrm{P} 6)$. The polysarcosine macroinitiator (111.9 mg, $9.2 \mu \mathrm{mol}$, and 1.0 equiv) was weighed into a predried Schlenk tube and dried by azeotropic distillation with toluene in vacuo twice. Next, the macroinitiator was dissolved in freshly degassed dry DMF $(1.45 \mathrm{~mL})$ and cooled to $-10{ }^{\circ} \mathrm{C}$, and $S$-ethylsulfonyl-Lcysteine NCA ( $33.0 \mathrm{mg}, 138 \mu \mathrm{mol}$, and 15 equiv) was added as a stock solution in dry DMF. The polymerization was performed at an overall mass concentration of $\beta=100 \mathrm{~g} \cdot \mathrm{L}^{-1}$ and monitored by IR spectroscopy. After 5 days, full conversion was observed, and the polymer was precipitated in THF. The suspension was centrifuged (4500 rpm, $15 \mathrm{~min}$, and $4{ }^{\circ} \mathrm{C}$ ) and decanted. This procedure was repeated twice concluding with pure diethyl ether. The product was dried in vacuo yielding $\mathrm{pSar}_{n}-b-\mathrm{p}(\mathrm{DL}) \mathrm{Cys}_{m}(\mathrm{P} 3)$ as a colorless solid $(130 \mathrm{mg}, 93 \%) .{ }^{1} \mathrm{H}$ NMR (400 MHz, DMSO-d $): \delta$ (ppm) 9.04-8.59 (b s, $1 \mathrm{mH}, \mathrm{NHCO}), 4.90-4.60$ (m, $\left.1 \mathrm{mH}, \alpha-\mathrm{CH}_{(\mathrm{DL}-\mathrm{Cys})}\right), 4.49-3.78$ (m, $\left.2 \mathrm{nH},-\mathrm{CH}_{2}-(\mathrm{Sar})\right), 3.69-3.41\left(\mathrm{~m}, 4 \mathrm{mH},-\mathrm{CH}_{2} \mathrm{~S}-,-\mathrm{SO}_{2} \mathrm{CH}_{2}-\right)$, $3.06-2.61\left(\mathrm{~m}, 3 \mathrm{nH},-\mathrm{CH}_{3(\mathrm{Sar})}\right), 1.36-1.21\left(\mathrm{t}, 3 \mathrm{mH},-\mathrm{CH}_{3(\mathrm{DL}-\mathrm{Cys})}\right)$.

Polysarcosine ${ }_{n}$-block-poly(S-ethylsulfonyl-L-cysteine) ${ }_{p}$ $\left(\right.$ pSar $\left._{n}-b-\mathrm{p}(\mathrm{L}) \mathrm{Cys}_{p}\right){ }^{n}\left(\mathrm{P7}\right.$-P10). ${ }^{1} \mathrm{H}$ NMR (400 MHz, DMSO-d $\left.d_{6}\right): \delta$ (ppm) 8.75 (b s, 1pH, NHCO), 4.69 (m, 1pH, $\left.\alpha-\mathrm{CH}_{(\mathrm{L}-\mathrm{Cys})}\right)$ ), 4.49$3.78\left(\mathrm{~m}, 2 \mathrm{nH},-\mathrm{CH}_{2}-(\mathrm{Sar})\right), 3.69-3.41\left(\mathrm{~m}, 4 \mathrm{pH},-\mathrm{CH}_{2} \mathrm{~S}-\right.$, $\left.-\mathrm{SO}_{2} \mathrm{CH}_{2}-\right)$, $3.06-2.61\left(\mathrm{~m}, 3 \mathrm{pH},-\mathrm{CH}_{3(\mathrm{Sar})}\right), 1.30(\mathrm{t}, 3 \mathrm{pH}$, $\left.-\mathrm{CH}_{3}(\mathrm{~L}-\mathrm{C} y \mathrm{~s})\right)$.

Polysarcosine ${ }_{n}$-block-poly(S-ethylsulfonyl-L-homocysteine) $\left(\mathrm{pSar}_{n}-b-\mathrm{p}(\mathrm{L}) \mathrm{Hcy}{ }_{q}\right)(\mathrm{P} 11-\mathrm{P} 14) .{ }^{1} \mathrm{H}$ NMR $\left(400 \mathrm{MHz}, \mathrm{DMSO}-d_{6}\right): \delta$ (ppm) $8.34(\mathrm{~b} \mathrm{~s}, 1 \mathrm{qH}, \mathrm{NHCO}), 4.56-3.75(\mathrm{~m}, 2 \mathrm{nH}+1 \mathrm{qH}$, $\left.-\mathrm{CH}_{2}-(\mathrm{Sar}), \alpha-\mathrm{CH}_{(\mathrm{L}-\mathrm{Hcy})}\right), 3.64-3.45\left(\mathrm{~m}, 2 \mathrm{qH},-\mathrm{SO}_{2} \mathrm{CH}_{2}-\right)$, 3.19$3.08\left(\mathrm{~m}, 2 \mathrm{qH},-\mathrm{CH}_{2} \mathrm{~S}-\right)$, 3.06-2.61 (m, 3nH, $\left.-\mathrm{CH}_{3(\mathrm{Sar})}\right), 2.18-1.85$ $\left(\mathrm{m}, 2 \mathrm{qH},-\mathrm{CH}_{2}-\mathrm{CH}_{2} \mathrm{~S}-\right), 1.30\left(\mathrm{t}, 3 \mathrm{qH},-\mathrm{CH}_{3}(\mathrm{~L}-\mathrm{Hcy})\right)$.

Cross-Linker Synthesis. The synthesis of $(R)$-lipoic acid hydrazide (3) was performed in a two-step synthesis via $(R)$-methyl lipoate (2) starting from $(R)$-lipoic acid $(1)$. The respective protocols were adapted and modified from Hassan and Maltman and Koufaki et al. $^{51,52}$

(R)-Lipoic acid ( $2.0 \mathrm{~g}, 9.69 \mathrm{mmol}$, and 1.0 equiv) was dissolved in $20 \mathrm{~mL}$ of methanol, and a catalytic amount of sulfuric acid $(5.2 \mu \mathrm{L}$, $0.10 \mathrm{mmol}$, and 0.01 equiv) was added. The reaction mixture was stirred at room temperature for $18 \mathrm{~h}$ and protected from light. The solvent was removed under reduced pressure, and the crude solid was redissolved in dichloromethane. The organic phase was washed with 

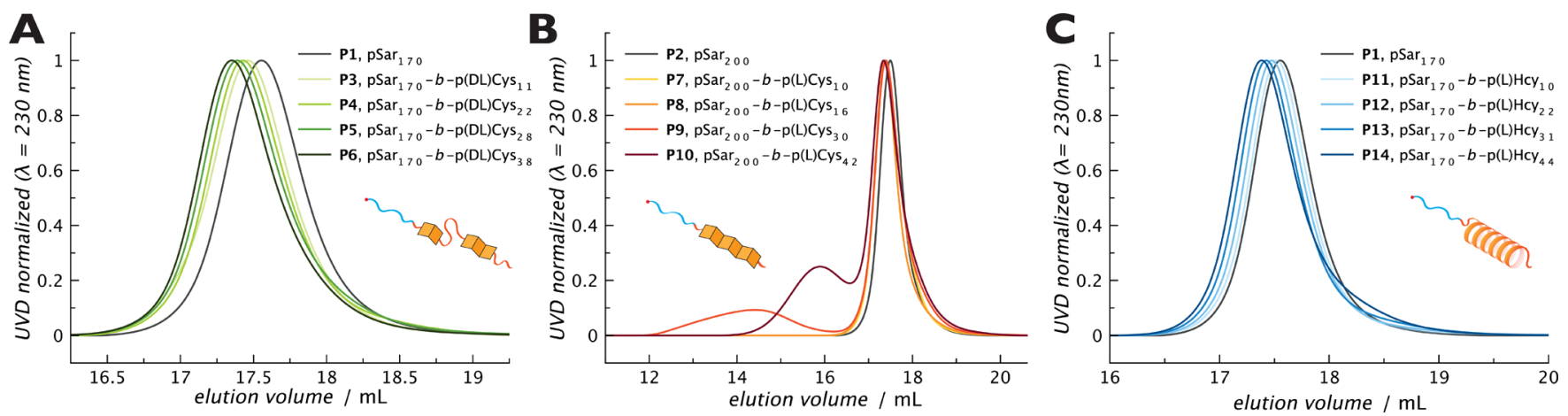

Figure 1. Analytical gel permeation chromatography in HFIP. (A) pSar- $b$-p(DL)Cys (P3-P6), (B) pSar-b-p(L)Cys (P7-P10), and (C) pSar-b$\mathrm{p}(\mathrm{L})$ Hcy (P11-P14), with the respective pSar macroinitiators (P1 and P2).

saturated $\mathrm{NaHCO}_{3}$ solution and brine, dried over magnesium sulfate, filtered, and concentrated in vacuo. (R)-Methyl lipoate (2) was obtained as a yellow oil $(1.90 \mathrm{~g}, 94 \%)$ and used without further purification. ${ }^{1} \mathrm{H}$ NMR (400 MHz, DMSO- $d_{6}$ ): $\delta$ (ppm) 3.25-3.03 (s $\left.+\mathrm{m}, 4 \mathrm{H},-\mathrm{CH}-,-\mathrm{OCH}_{3}\right), 3.15\left(\mathrm{~m}, 2 \mathrm{H},-\mathrm{SCH}_{2}-\right), 2.42(\mathrm{~m}, 1 \mathrm{H}$, $\left.-\mathrm{SCH}_{2} \mathrm{CH}_{2}-\right), 2.31\left(\mathrm{t},{ }^{3} \mathrm{~J}=7.3 \mathrm{~Hz}, 2 \mathrm{H},-\mathrm{COCH}_{2}-\right), 1.87(\mathrm{~m}, 1 \mathrm{H}$, $\left.-\mathrm{SCH}_{2} \mathrm{CH}_{2}-\right)$, $1.73-1.48\left(\mathrm{~m}, 4 \mathrm{H},-\beta-\mathrm{CH}_{2},-\delta-\mathrm{CH}_{2}\right), 1.42-1.30$ (m, $2 \mathrm{H},-\gamma-\mathrm{CH}_{2}-$ ).

(R)-Methyl lipoate (2) (1.90 g, $8.6 \mathrm{mmol}$, and 1.0 equiv) was dissolved in $10 \mathrm{~mL}$ of methanol, and hydrazine hydrate $(1.3 \mathrm{~mL}, 25.8$ $\mathrm{mmol}$, and 3.0 equiv) was added in one portion. The reaction mixture was stirred at room temperature for $72 \mathrm{~h}$ in the absence of light. The solution was concentrated in vacuo and redissolved in chloroform, and the organic layer was washed with brine. The organic phase was dried over magnesium sulfate, filtered, and concentrated under reduced pressure. $(R)$-Lipoic acid hydrazide (3) was obtained as a yellow oil $(1.22 \mathrm{~g}, 64 \%)$ and used without further purification. ${ }^{1} \mathrm{H}$ NMR (400 MHz, DMSO- $d_{6}$ ): $\delta$ (ppm) 8.92 (b s, $1 \mathrm{H}, \mathrm{NHCO}$ ), 4.14 (b s, $\left.2 \mathrm{H},-\mathrm{NH}_{2}\right), 3.60(\mathrm{~m}, 1 \mathrm{H},-\mathrm{CH}-), 3.14\left(\mathrm{~m}, 2 \mathrm{H},-\mathrm{SCH}_{2}-\right)$, $2.40\left(\mathrm{~m}, 1 \mathrm{H},-\mathrm{SCH}_{2} \mathrm{CH}_{2}-\right), 2.00\left(\mathrm{t},{ }^{3} \mathrm{~J}=7.3 \mathrm{~Hz}, 2 \mathrm{H},-\mathrm{COCH}_{2}\right)$, $1.85\left(\mathrm{~m}, 1 \mathrm{H},-\mathrm{SCH}_{2} \mathrm{CH}_{2}-\right), 1.70-1.43\left(\mathrm{~m}, 4 \mathrm{H},-\beta-\mathrm{CH}_{2},-\delta-\mathrm{CH}_{2}\right)$, $1.38-1.27\left(\mathrm{~m}, 2 \mathrm{H},-\gamma-\mathrm{CH}_{2}-\right)$. ESI-MS $(m / z=243.20):[\mathrm{M}+\mathrm{Na}]^{+}$, M (calc.), $243.06 \mathrm{~g} \cdot \mathrm{mol}^{-1}$.

Aggregation Curves. The respective polypept(o)ide (P3-P14) was dissolved in DMAc at a concentration of $7.5 \mathrm{~g} \cdot \mathrm{L}^{-1}$, and $300 \mu \mathrm{L}$ was placed into a solvent-resistant plastic cuvette for DLS measurement. Aqueous sodium acetate buffer ( $1 \mathrm{mM}, \mathrm{pH} 4.75)$ was added in steps of 5 to $20 \mu \mathrm{L}$, and the derived count rate was obtained by DLS with automated positioning and attenuator adjustment at multiple scans. Data were analyzed using Origin 7.5 (OriginLab, USA) and a sigmoidal fit (model: Dose Response).

Self-Assembly and Core Cross-Linking. The preparation of core cross-linked polymeric micelles was adapted and modified from Klinker et al. ${ }^{50}$ Each polypept(o)ide was assembled at the respective turning point.

$\mathrm{pSar}_{170^{-}} b-\mathrm{p}(\mathrm{DL}) \mathrm{Cys}_{11}$ (P3) was dissolved in DMAc at a concentration of $7.5 \mathrm{~g} \cdot \mathrm{L}^{-1}$ for $1 \mathrm{~h}$. Next, 51 vol \% $1 \mathrm{mM}$ acetate buffer ( $\mathrm{pH} 4.75)$ was added, and the solution was left to equilibrate at room temperature for $3 \mathrm{~h}$ followed by dialysis against $1 \mathrm{mM}$ acetate buffer ( $\mathrm{pH}$ 4.75). The solution was filtered (GHP 450) and concentrated to $7 \mathrm{~g} \cdot \mathrm{L}^{-1}$ by spin filtration (Amicon Ultra; MWCO, $3 \mathrm{kDa}$ ), yielding the micelle solution. For cross-linking, in a separate flask, lipoic acid hydrazide was dissolved in ethanol at a concentration of $\beta=20 \mathrm{~g} \cdot \mathrm{L}^{-1}$, and one equivalent of an aqueous solution of tris (2carboxyethyl)phosphine hydrochloride (TCEP. $\mathrm{HCl})\left(50 \mathrm{~g} \cdot \mathrm{L}^{-1}\right)$ was added per disulfide. After $18 \mathrm{~h}$, the cross-linker solution was added to the micelle solution at equimolar amounts of thiols per cysteines. The reaction mixture was stirred at room temperature for $48 \mathrm{~h}$. To remove the residual cross-linker and free polymer, the solution was dialyzed against DMSO and Milli- $\mathrm{Q}$ water (MWCO, 6-8 kDa) followed by repetitive spin filtration (Amicon Ultra; MWCO, $100 \mathrm{kDa}$ ). Both micelles and core cross-linked micelles were analyzed by DLS. For
CCPMs, the absence of the free polymer was verified by gel permeation chromatography in hexafluoroisopropanol.

\section{RESULTS AND DISCUSSION}

To investigate the influence of secondary structure on the selfassembly of thiol-reactive polypept(o)ides, amphiphilic block copolymers of racemic polysarcosine-block-poly ( $S$-ethylsulfonyl-DL-cysteine) (pSar-b-p(DL)Cys, P3-P6), enantiopure polysarcosine-block-poly (S-ethylsulfonyl-L-cysteine) (pSar- $b$-p (L)Cys, P7-P10), and polysarcosine-block-poly(S-ethylsulfonylL-homocysteine) (pSar- $b$-p(L)Hcy, P11-P14) have been prepared.

As shown in Scheme 1, all polymers were synthesized by living ring-opening NCA polymerization. Respective secondary structures of the hydrophobic blocks, e.g., $\alpha$-helices, $\beta$-sheets, or disrupted $\beta$-sheets, are illustrated as reported for the parent homopolymers. ${ }^{47-49}$ The polymerization of sarcosine NCA was initiated by $\mathrm{N}$-Boc-1,2-diaminoethane, and pSar (P1 and P2) was end-capped with perfluorophenyl-4-azidobutanoate before the Boc group was removed and block copolypept(o)ides were obtained from pSar macroinitiators. This strategy allows for trifold copolymer modification by $[3+2]$ cycloaddition reactions with alkyne-modified dyes or targeting moieties, reactions with reactive esters at the amine end-group, and reactions addressing the $S$-ethylsulfonyl group. ${ }^{53}$

For the preparation of block copolymers, when reacted at $-10{ }^{\circ} \mathrm{C}$ in DMF, the reactive $S$-ethylsulfonyl-protecting group remains intact, ${ }^{46}$ and a shift compared to the pSar macroinitiator can be detected by GPC in hexafluoroisopropanol (HFIP) (Figure 1), which indicates successful chain extension. In detail, symmetric and monomodal molecular weight distributions with a distinct shift for increasing repetitive units were detected for $\mathrm{pSar}_{n}-b-\mathrm{p}(\mathrm{DL}) \mathrm{Cys}_{m}$ with $X_{m}$ from 11 to 38 (P3-P6) and $\mathrm{pSar}_{n}-b-\mathrm{p}(\mathrm{L}) \mathrm{Hcy}_{q} X_{q}=10$ to 44 (P11-P14) (Figure 1A,C). Contrariwise, the strong antiparallel $\beta$-sheets of enantiopure $\mathrm{p}(\mathrm{L}) \mathrm{Cys}_{p}$ could not be resolved by HFIP for higher chain lengths, accounting for bimodal GPC in Figure 1B and the corresponding broad dispersity for block copolymers with $X_{p}>16$. When analyzed by DOSY NMR in DMSO- $d_{6}$, however, only one diffusing species could be detected for all $\mathrm{pSar}_{n}-b-\mathrm{p}(\mathrm{L}) \mathrm{Cys}_{n}$ polymers $(\mathrm{P} 7-\mathrm{P} 10)$ verifying successful polymer synthesis and the absence of homopolymers (see the Supporting Information, Figures S26-S29).

Since $\alpha$-helices promote NCA polymerization at pseudo first-order kinetics, ${ }^{1,12,20}$ full conversion was detected for the polymerization of $\mathrm{L}-\mathrm{Hcy}\left(\mathrm{SO}_{2} \mathrm{Et}\right)-\mathrm{NCA}$, and thus, chain lengths determined for $\mathrm{pSar}-b-\mathrm{p}(\mathrm{L}) \mathrm{Hcy}$ are in good agreement with the 
Table 1. Analytical Results of the Polymer Synthesis

\begin{tabular}{|c|c|c|c|c|c|c|c|}
\hline polymer & $X_{n}(\mathrm{pSar})^{a}$ & $X_{m, p, \text { and } q}$ (reactive block, calc.) & $X_{m, p, \text { and } q}(\text { reactive block })^{b}$ & $M_{n}^{c}(\mathrm{kDa})$ & $M_{w}{ }^{c}(\mathrm{kDa})$ & $\boxplus^{c}$ & wt $\%$ reactive block \\
\hline $\mathrm{P} 1, \mathrm{pSar}_{170}$ & 170 & & & 37.7 & 45.7 & 1.21 & \\
\hline P2, pSar $_{200}$ & 200 & & & 39.8 & 47.9 & 1.20 & \\
\hline P3, $\mathrm{pSar}_{170^{-}} b-\mathrm{p}(\mathrm{DL}) \mathrm{Cys}_{11}$ & 170 & 15 & 11 & 42.6 & 53.0 & 1.24 & 15 \\
\hline P4, $\mathrm{pSar}_{170^{-}} b-\mathrm{p}(\mathrm{DL}) \mathrm{Cys}_{22}$ & 170 & 30 & 22 & 41.5 & 53.4 & 1.28 & 26 \\
\hline P5, $\mathrm{pSar}_{170^{-}} b-\mathrm{p}(\mathrm{DL}) \mathrm{Cys}_{28}$ & 170 & 50 & 28 & 42.5 & 54.3 & 1.28 & 31 \\
\hline $\mathrm{P} 6, \mathrm{pSar}_{170}-b-\mathrm{p}(\mathrm{DL}) \mathrm{Cys}_{38}$ & 170 & 50 & 38 & 46.1 & 57.2 & 1.24 & 38 \\
\hline P7, $\mathrm{pSar}_{200}-b-\mathrm{p}(\mathrm{L}) \mathrm{Cys}_{10}$ & 200 & 20 & 10 & 42.3 & 53.4 & 1.26 & 12 \\
\hline P8, $\mathrm{pSar}_{200}-b-\mathrm{p}(\mathrm{L}) \mathrm{Cys}_{16}$ & 200 & 30 & 16 & 41.9 & 56.0 & 1.33 & 18 \\
\hline $\mathrm{P} 9, \mathrm{pSar}_{200}-b-\mathrm{p}(\mathrm{L}) \mathrm{Cys}_{30}$ & 200 & 50 & 30 & 47.7 & 215.5 & 4.52 & 29 \\
\hline $\mathrm{P} 10, \mathrm{pSar}{ }_{200}-b-\mathrm{p}(\mathrm{L}) \mathrm{Cys}_{42}$ & 200 & 50 & 42 & 41.9 & 122.1 & 2.45 & 37 \\
\hline $\mathrm{P} 11, \mathrm{pSar}{ }_{170}-b-\mathrm{p}(\mathrm{L}) \mathrm{Hcy}_{10}$ & 170 & 11 & 10 & 38.5 & 48.1 & 1.25 & 15 \\
\hline P12, $\mathrm{pSar}_{170^{-}} b-\mathrm{p}(\mathrm{L}) \mathrm{Hcy}_{22}$ & 170 & 22 & 22 & 38.3 & 49.9 & 1.30 & 27 \\
\hline P13, pSar ${ }_{170^{-}} b-\mathrm{p}(\mathrm{L}) \mathrm{Hcy}_{31}$ & 170 & 35 & 31 & 38.9 & 52.5 & 1.35 & 35 \\
\hline P14, pSar ${ }_{170^{-}} b-\mathrm{p}(\mathrm{L}) \mathrm{Hcy}_{44}$ & 170 & 50 & 44 & 39.2 & 54.0 & 1.37 & 43 \\
\hline
\end{tabular}

${ }^{a}$ Determined by HFIP GPC relative to pSar standards. ${ }^{29}{ }^{b}$ Determined by ${ }^{1} \mathrm{H}$ NMR. ${ }^{c}$ Determined by HFIP GPC relative to PMMA standards.

calculated chain lengths (Table 1). In contrast, the NCA polymerization of both, enantiopure and racemic L-Cys$\left(\mathrm{SO}_{2} \mathrm{Et}\right)-\mathrm{NCA}$ and $\mathrm{DL}-\mathrm{Cys}\left(\mathrm{SO}_{2} \mathrm{Et}\right)-\mathrm{NCA}$, was governed by insoluble $\beta$-sheets referring to an Avrami type of chain growth. ${ }^{47,48}$ Consequently, polymerizations were stopped when no further progress could be detected by FT-IR spectroscopy, accounting for the deviation between calculated and obtained chain lengths. ${ }^{54}$ Of note, in our case, the addition of chaotropic thiourea, freshly purified by vacuum sublimation, did not help to overcome this limitation but solely resulted in homopolymer formation (Figure S1). ${ }^{55}$ Nevertheless, as summarized in Table 1 , three sets containing four reactive amphiphilic polypept(o)ides have been prepared successfully. These polymers are characterized by comparable chain lengths of 170 and 200 for hydrophilic pSar and 10 to 44 for the hydrophobic reactive $S$-ethylsulfonyl-protected blocks. The respective block ratios correspond to similar hydrophobic segments ranging from 12 to $43 \mathrm{wt} \%$, well suitable for selfassembly to micellar structures. ${ }^{56-58}$

To verify the secondary structure, block copolypept(o)ides were analyzed by FT-IR spectroscopy in the solid state. ${ }^{59,60}$ The characteristic signals for an $\alpha$-helix can generally be found at $1650 \mathrm{~cm}^{-1}$ (amide I) and $1546 \mathrm{~cm}^{-1}$ (amide II), while for $\beta$ sheets, these peaks can be observed at $1630 \mathrm{~cm}^{-1}$ (amide I) and $1530 \mathrm{~cm}^{-1}$ (amide II), as well as $1656 \mathrm{~cm}^{-1}$ (amide I) and $1535 \mathrm{~cm}^{-1}$ (amide II) for random coil structures. ${ }^{1,59-61}$ As shown in Figure 2A, predominant signals of the amide bands at 1546 and $1317 \mathrm{~cm}^{-1}$ (amide II, amide III; blue arrows) can be assigned to the $\alpha$-helical $\mathrm{p}(\mathrm{L})$ Hcy block despite the coexistence with the random coil of polysarcosine, which overlaps for the amide I peak. Furthermore, CD spectroscopy in HFIP showed an increasing concision of the characteristic signals (minima at 212 and $226 \mathrm{~nm}$, maximum at $194 \mathrm{~nm}$ ) for growing $\mathrm{p}(\mathrm{L}) \mathrm{Hcy}$ chain lengths confirming the $\alpha$-helical structure (Figure S2) ${ }^{62}$ For enantiopure pSar- $b-\mathrm{p}(\mathrm{L}) \mathrm{Cys}$ copolymers, the shoulder at $1703 \mathrm{~cm}^{-1}$ (red arrow) accounts for the antiparallel orientation of the $\beta$-sheets, while no characteristic peaks can be distinguished for racemic pSar- $b$-p (DL)Cys copolymers. When analyzed by NMR spectroscopy (Figure 2B), block copolymers of pSar- $b$-p (DL)Cys show much broader peaks compared to enantiopure pSar- $b-\mathrm{p}(\mathrm{L}) \mathrm{Cys}$, suggesting a rather atactic polymer structure similar to observations for the racemic $\mathrm{p}(\mathrm{DL})$ Cys homopolymers. ${ }^{48}$ Taken together and referring to the secondary structures detected for the respective homo-
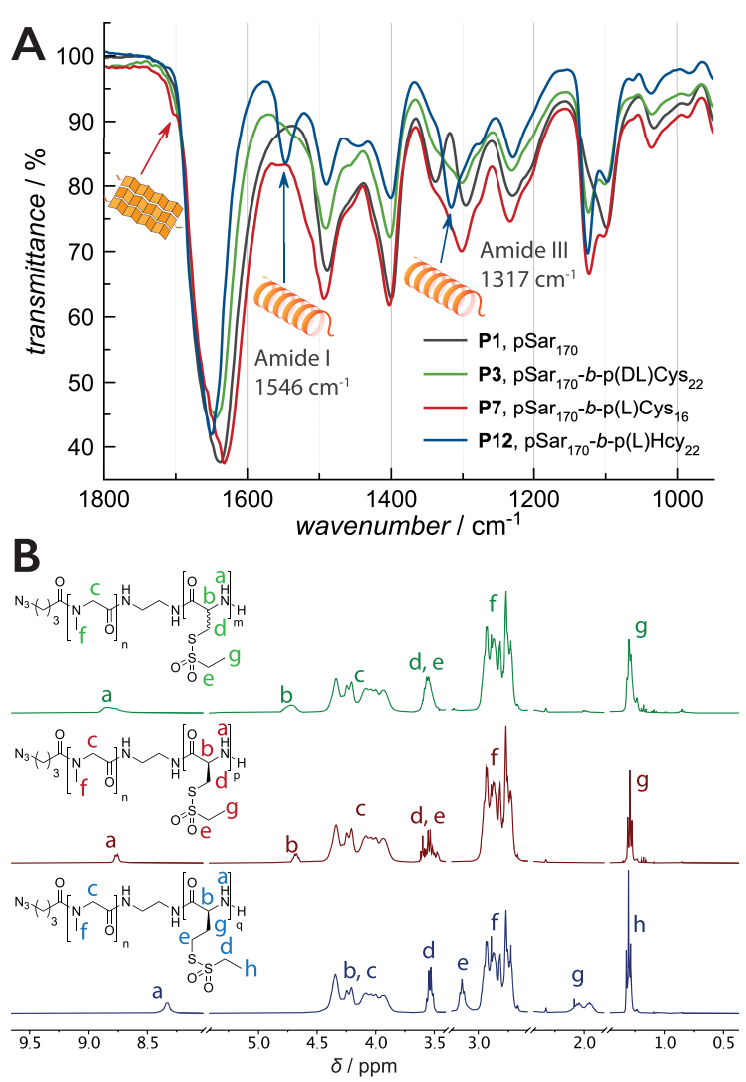

Figure 2. Secondary structure analysis of pSar- $b$-p(DL)Cys, pSar- $b$ $\mathrm{p}(\mathrm{L})$ Cys, and pSar- $b$-p(L)Hcy. (A) FT-IR spectroscopy and (B) ${ }^{1} \mathrm{H}$ NMR spectroscopy.

polypeptides in solution by circular dichroism spectroscopy, ${ }^{47-49}$ GPC, IR, and NMR spectroscopy confirm the successful preparation of reactive block copolypept(o)ides with secondary structures varying from $\alpha$-helices to disrupted or antiparallel $\beta$-sheets. ${ }^{63,64}$

The influence of secondary structure on solution selfassembly was investigated by a titration experiment. As illustrated in Figure 3A, the reactive polypept(o)ides were dissolved in a good solvent, $\mathrm{N}, \mathrm{N}$-dimethylacetamide (DMAc), and water, equipped with $1 \mathrm{mM}$ sodium acetate ( $\mathrm{pH} 4.75)$, was added stepwise. When a certain buffer concentration is reached, polymers start to assemble, and the scattering 


\section{A Aggregation in the dynamic range}

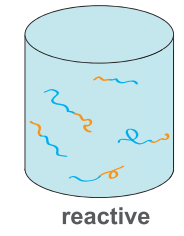

polypept(o)ides dissolved in DMAc

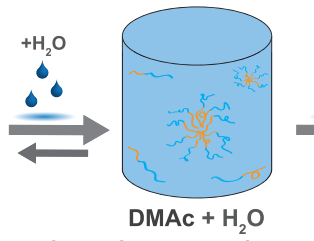

dynamic aggregation starts self-assembly completed
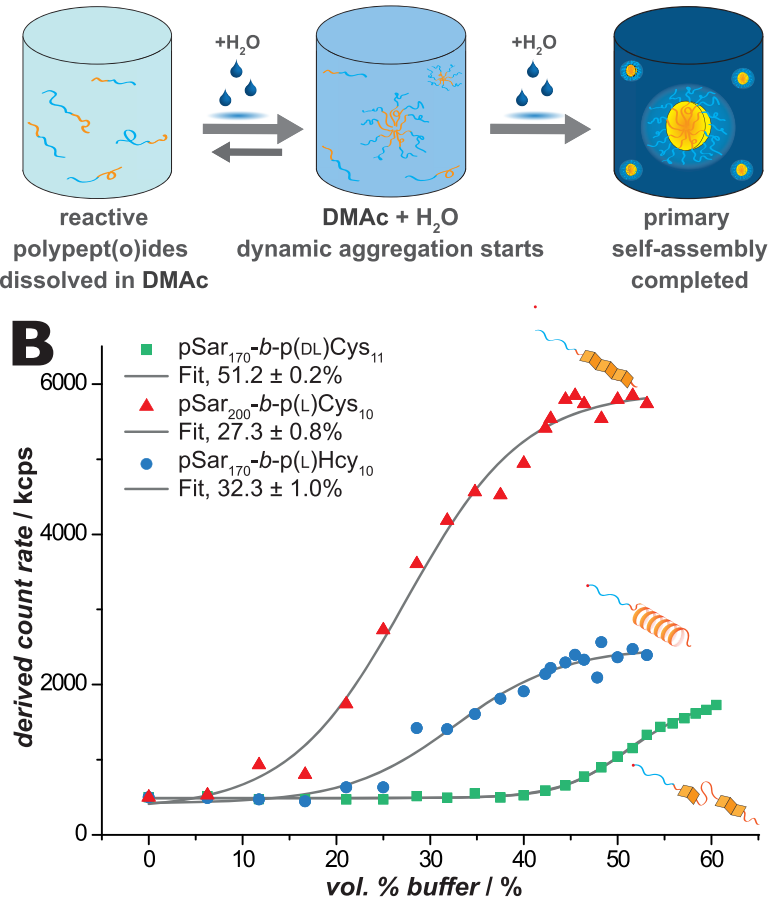

Figure 3. Influence of the secondary structure on the aggregation behavior. (A) Schematic illustration of the dynamic range. (B) Aggregation curve of polypept(o)ides (P3, P7, and P11) with sigmoidal fit.

intensity increases, which correlates with the derived count rate detected by DLS. The count rate continues to increase as long as new micelles form or larger aggregates grow $\left(I \sim R^{6}\right){ }^{63}$ Finally, a plateau is reached when the concentration of the block-selective solvent exceeds a certain limit. Due to the low solubility of the free polymer, micelles remain stable. ${ }^{56,66,67}$ Besides additional parameters such as solvents and polymer concentration, the dynamic range of self-assembly is specific for each polymer.

For head-to-head comparison, racemic pSar- $b$-p(DL)Cys, enantiopure $\mathrm{pSar}-b-\mathrm{p}(\mathrm{L}) \mathrm{Cys}$, and $\mathrm{pSar}-b-\mathrm{p}(\mathrm{L}) \mathrm{Hcy}$ were dissolved in DMAc at equal concentrations, and the aqueous buffer was added at comparable time intervals. Interestingly, the three copolymers of comparable chain lengths showed significant variations in their aggregation behavior (Figure 3B). Sigmoidal shapes were obtained for all aggregation curves; however, the sigmoidal fit revealed a turning point at $27.3 \pm$ $0.8 \%$ for the enantiopure $\mathrm{pSar}_{200}-b-\mathrm{p}(\mathrm{L}) \mathrm{Cys}_{10}$, while turning points of $51.2 \pm 0.2$ and $32.3 \pm 1.0 \%$ were derived for racemic $\mathrm{pSar}_{170}-b-\mathrm{p}(\mathrm{DL}) \mathrm{Cys}_{11}$ and $\mathrm{pSar}_{170}-b-\mathrm{p}(\mathrm{L}) \mathrm{Hcy}_{10}$, respectively. Moreover, the final plateau level of $\mathrm{pSar}_{200}-b-\mathrm{p}(\mathrm{L}) \mathrm{Cys}_{10}$ was found to be $\sim 3$-fold higher compared to racemic $\mathrm{pSar}_{170^{-}} b$ $\mathrm{p}(\mathrm{DL}) \mathrm{Cys}_{11}$ and $\sim 2$-fold higher compared to $\mathrm{pSar}_{170^{-}}-b$ $\mathrm{p}(\mathrm{L}) \mathrm{Hcy}_{10}$. As the primary structure does not differ significantly among the selected copolymers, the observed effects can be attributed to the variation of the secondary structure, which confirms antiparallel $\beta$-sheets as an assemblypromoting character stronger than $\alpha$-helices, likely caused by attractive interactions between individual $\beta$-sheets.

When the chain lengths of the hydrophobic polypeptide blocks are increased, turning points generally shift to aggregation at lower buffer concentrations for all copolymers (Figure 4). In addition, the dynamic range, thus the area between the start of the aggregation and the primary plateau, becomes narrower by increasing the hydrophobic segment. As such, the dynamic range extends from 20 to 50 vol \% buffer for $\mathrm{pSar}_{170}-b-\mathrm{p}(\mathrm{L}) \mathrm{Hcy}_{10}$ but from 15 to 30 vol \% buffer for $\mathrm{pSar}_{170^{-}}$ $b$-p $(\mathrm{L}) \mathrm{Hcy}_{44}$. Furthermore, the trend of antiparallel $\beta$-sheets as being the strongest promoter of self-assembly can be confirmed by the shift of the turning point from $27.3 \pm 0.8$ vol \% for $\mathrm{pSar}_{200}-b-\mathrm{p}(\mathrm{L}) \mathrm{Cys}_{10}$ to concentrations as low as $8.7 \pm$ 0.3 vol \% buffer for $\mathrm{pSar}_{200}-b-\mathrm{p}(\mathrm{L}) \mathrm{Cys}_{42}$. Interestingly, for $\mathrm{pSar}_{200}-b-\mathrm{p}(\mathrm{L}) \mathrm{Cys}_{30}$ and $\mathrm{pSar}_{200}-b-\mathrm{p}(\mathrm{L}) \mathrm{Cys}_{42}$, the primary aggregation seems to be accompanied by a secondary aggregation, as the sigmoidal fit cannot be applied over the entire range, indicating further rearrangement of the initially formed micelles. ${ }^{68,69}$

Finally, the findings on the aggregation behavior were transferred to the preparation of core cross-linked polymeric micelles (CCPMs) from the reactive polypept(o)ides, as illustrated in Figure 5A. The copolymers were dissolved in DMAc and equilibrated by addition of buffer at their respective turning points, before solvent exchange was completed by dialysis. When analyzed by DLS (Figure 5B), both $\alpha$-helical pSar- $b$-p (L)Hcy and racemic pSar- $b$-p (DL)Cys yielded small polymeric micelles of similar size $\left(D_{h}, 36-44 \mathrm{~nm}\right)$ and a narrow PDI (0.04-0.15), despite increasing chain lengths of the respective hydrophobic blocks. In contrast, an increased size was detected for enantiopure pSar- $b$-p $(\mathrm{L})$ Cys $\left(D_{h}, 55-76\right.$ $\mathrm{nm}$ ) directing to larger structures for polymers with longer hydrophobic blocks. For further analysis, micelles were crosslinked by reaction of the $S$-ethylsulfonyl group with dihydrolipoic acid hydrazide (3), and the morphology of the
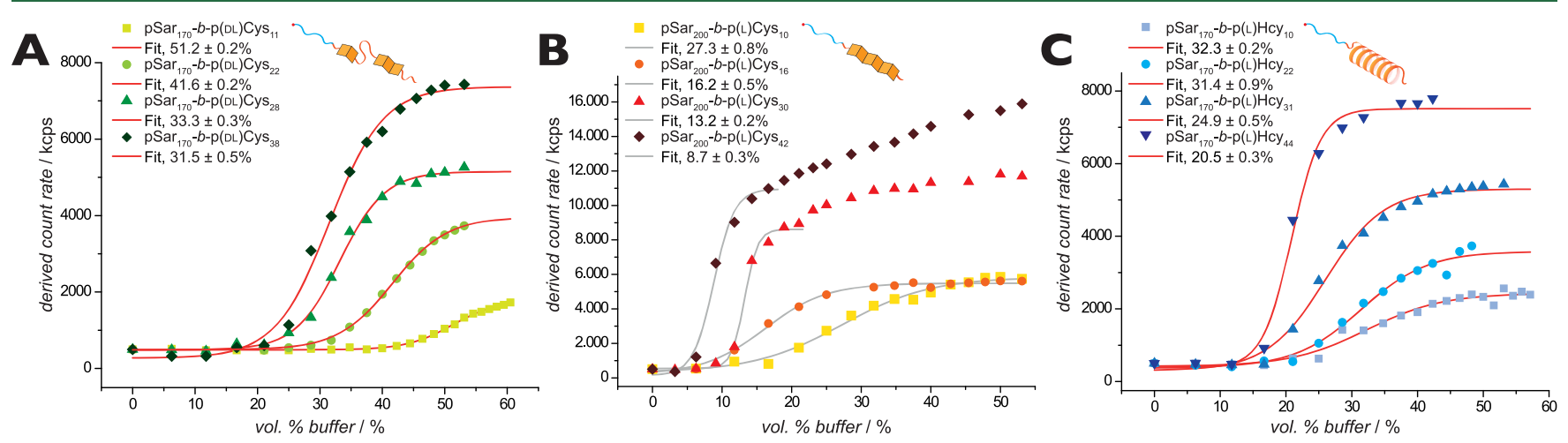

Figure 4. Aggregation curves for copolymers P3-P14. (A) pSar-b-p(DL)Cys, (B) pSar-b-p(L)Cys, and (C) pSar-b-p(L)Hcy. 


\section{A Self-Assembly and Core Cross-Linking}

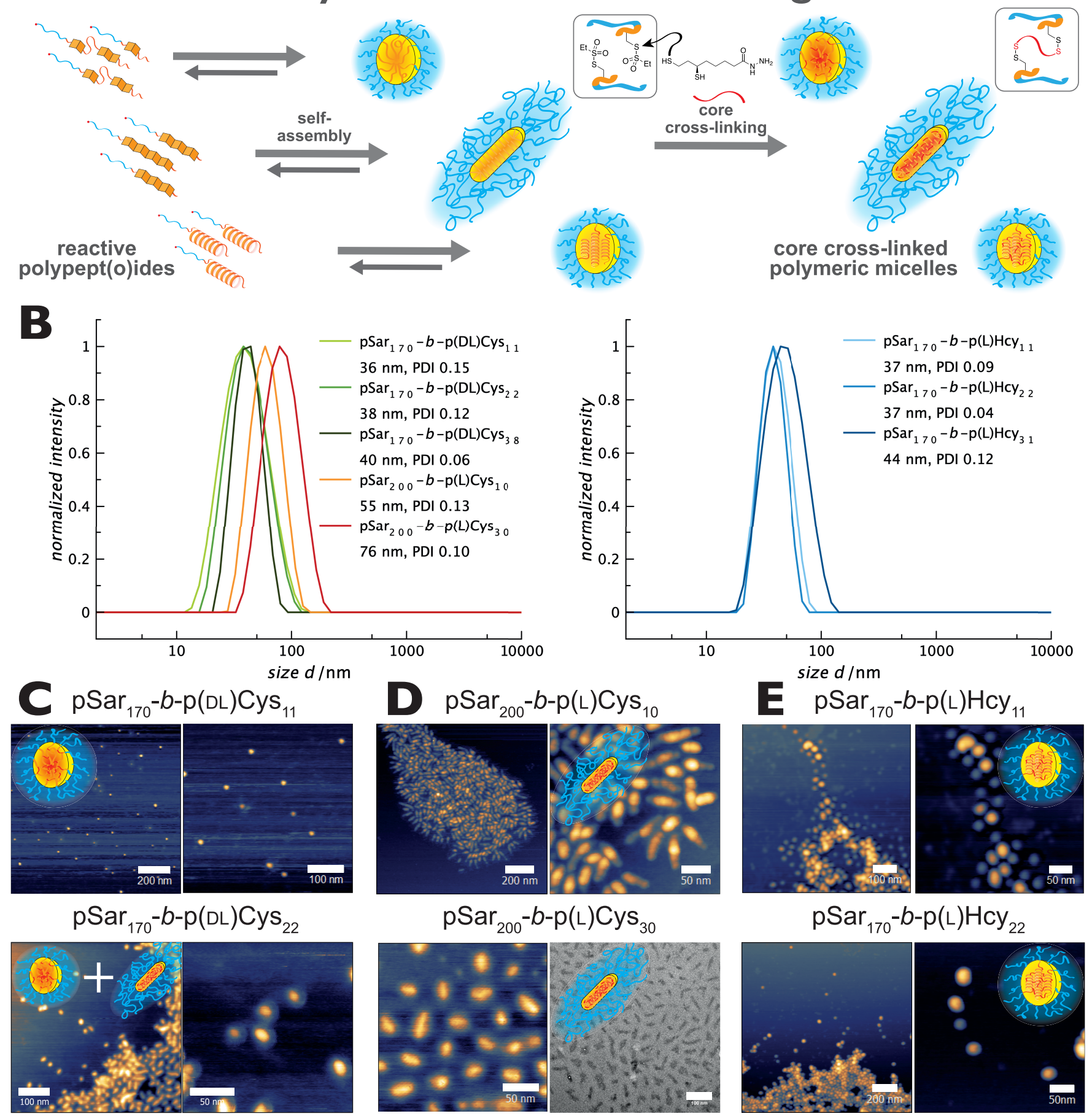

Figure 5. Self-assembly and core cross-linking. (A) Schematic illustration of secondary structure-driven self-assembly. (B) Single-angle DLS analysis of polymeric micelles (left: pSar- $b$ - $\mathrm{p}(\mathrm{DL})$ Cys and $\mathrm{pSar}-b-\mathrm{p}(\mathrm{L})$ Cys, right: $\mathrm{pSar}-\mathrm{b}-\mathrm{p}(\mathrm{L}) \mathrm{Hcy}$ ). Morphological analysis of core cross-linked polymeric micelles by AFM and cryoTEM: (C) pSar- $b$-p(DL)Cys, (D) pSar- $b$-p(L)Cys, and (E) pSar- $b$-p(L)Hcy.

obtained disulfide cross-linked micelles was investigated by AFM (Figure 5C-E and Figures S5-S8). Of note, the crosslinking reaction did not influence the overall size distribution (Figure S3). Analysis by AFM revealed spherical structures with diameters well below $50 \mathrm{~nm}$ for CCPMs from racemic pSar- $b$-p(DL)Cys containing 15 wt \% p(DL)Cys, while spherical to slightly elongated particles could be observed for 26 wt \% p(DL)Cys (Figure 5C and Figure S5). As shown by AFM and cryoTEM (Figure 5D and Figures S6 and S7), solely worm-like micelles were obtained for $\mathrm{pSar}-b$-p $(\mathrm{L})$ Cys containing both 12 and 29 wt \% enantiopure $\mathrm{p}(\mathrm{L})$ Cys, which corresponds well with previous findings as well as with the larger size determined by DLS. ${ }^{50}$ Spherical CCPMs only were obtained from $\alpha$-helical pSar- $b$-p(L)Hcy of 15 or 27 wt $\% \mathrm{p}(\mathrm{L}) \mathrm{Hcy}$, as shown in Figure 5E and Figure S8. ${ }^{70}$

Taken together, secondary structure formation is a major parameter affecting the self-assembly of polypept(o)ides. In direct comparison, the reactive amphiphilic block copolymer 
with an $\alpha$-helical segment, pSar- $b$-p(L)Hcy, only yielded spherical structures, whereas $\beta$-sheets in enantiopure pSar- $b$ $\mathrm{p}(\mathrm{L})$ Cys strongly direct self-assembly to worm-like particles and even affect racemic pSar- $b$-p(DL)Cys with longer hydrophobic segments.

\section{CONCLUSIONS}

In conclusion, our head-to-head comparison underlines the influence of secondary structure formation on the aggregation and self-assembly of block copolypept(o)ides. Herein, we reported the successful synthesis of reactive, $S$-ethylsulfonylprotected pSar- $b$-p (DL)Cys, pSar- $b$-p (L)Cys, and pSar- $b$-p (L)Hcy. Despite comparable primary structures, the secondary structure of these block copolymers varies from disrupted $\beta$ sheets to antiparallel $\beta$-sheets and $\alpha$-helices, which impacts their tendency to self-assemble during the solvent switch. The antiparallel $\beta$-sheets of enantiopure pSar- $b$-p(L)Cys strongly induce early aggregation compared to the racemic pSar- $b$ $\mathrm{p}$ (DL)Cys counterpart and narrow the dynamic range. Moreover, the $\alpha$-helix in pSar- $b$-p(L)Hcy favors the formation of spherical structures, whereas $\beta$-sheets direct self-assembly into worm-like micelles for enantiopure pSar- $b$ - $\mathrm{p}(\mathrm{L}) \mathrm{Cys}$ and even influence the self-assembly of pSar- $b$-p(DL)Cys in which the antiparallel orientation is disrupted by the racemic hydrophobic block. A detailed understanding of the secondary structure enables powerful control over the morphology of micellar assemblies and fine-tuning of particle properties beyond the hydrophilic-hydrophobic ratio. This implies a major significance for polypeptides as drug delivery systems and in materials science.

\section{ASSOCIATED CONTENT}

\section{SI Supporting Information}

The Supporting Information is available free of charge at https://pubs.acs.org/doi/10.1021/acs.biomac.1c00253.

HFIP GPC of polymerizations in the presence of thiourea; CD spectra, DLS, GPC, and additional AFM/cryoTEM images of core cross-linked polymeric micelles; NMR data of polymer and cross-linker synthesis; DOSY NMR spectroscopy of (co-)polymers (PDF)

\section{AUTHOR INFORMATION}

\section{Corresponding Author}

Matthias Barz - Leiden Academic Centre for Drug Research (LACDR), Leiden University, 2333 CC Leiden, The Netherlands; Department of Chemistry, Johannes Gutenberg University Mainz, 55128 Mainz, Germany; 이이.org/ 0000-0002-1749-9034; Email: m.barz@lacdr.leidenuniv.nl

\section{Authors}

Tobias A. Bauer - Leiden Academic Centre for Drug Research (LACDR), Leiden University, 2333 CC Leiden, The Netherlands; Department of Chemistry, Johannes Gutenberg University Mainz, 55128 Mainz, Germany

Jan Imschweiler - Department of Chemistry, Johannes Gutenberg University Mainz, 55128 Mainz, Germany

Christian Muhl - Leiden Academic Centre for Drug Research (LACDR), Leiden University, 2333 CC Leiden, The Netherlands; Department of Chemistry, Johannes Gutenberg University Mainz, 55128 Mainz, Germany
Benjamin Weber - Department of Chemistry, Johannes Gutenberg University Mainz, 55128 Mainz, Germany

Complete contact information is available at:

https://pubs.acs.org/10.1021/acs.biomac.1c00253

\section{Author Contributions}

Experiment design, polymer synthesis, nanoparticle preparation, AFM, and CD measurements were performed by T.A.B., J.I. contributed to polymer synthesis and nanoparticle formation, and C.M. contributed to polymer synthesis. B.W. performed cryoTEM analysis. The manuscript was written by T.A.B. and M.B. The project was supervised by M.B. All authors have given approval to the final version of the manuscript.

Notes

The authors declare the following competing financial interest(s): Matthias Barz holds the patent Thiol-protected amino acid derivatives and uses thereof WO2015169908A1.

\section{ACKNOWLEDGMENTS}

We would like to acknowledge Holger Adam for support with AFM measurements, Dr. Frank Depoix for support and instruction on the cryoTEM, and Prof. Dr. Alexander Kros (Leiden University) for access to CD spectroscopy. T.A.B. would like to acknowledge the $\mathrm{HaVo}$ Stiftung and the Max Planck Graduate Center for financial support. T.A.B., C.M., B.W., and M.B. would like to acknowledge the SFB1066-2 for funding.

\section{ABBREVIATIONS}

AFM; atomic force microscopy; Boc; tert-butyloxycarbonyl; CCPM; core cross-linked polymeric micelle; CD; circular dichroism; DLS; dynamic light scattering; DMAc; $N, N$ dimethylacetamide; DMF; N,N-dimethylformamide; DMSO; dimethylsulfoxide; GPC; gel permeation chromatography; FTIR spectroscopy; Fourier transform infrared spectroscopy; HFIP; 1,1,1,3,3,3-hexafluoropropan-2-ol; MWCO; molecular weight cutoff; NCA; $N$-carboxyanhydride; pSar; polysarcosine; $\mathrm{p}(\mathrm{L})$ Cys; poly (S-ethylsulfonyl-L-cysteine); p(DL)Cys; poly $(S$ ethylsulfonyl-DL-cysteine); $\mathrm{p}(\mathrm{L}) \mathrm{Hcy}$; poly(S-ethylsulfonyl-L-homocysteine); cryoTEM; cryogenic transmission electron microscopy

\section{REFERENCES}

(1) Bonduelle, C. Secondary Structures of Synthetic Polypeptide Polymers. Polym. Chem. 2018, 9, 1517-1529.

(2) Kricheldorf, H. R.; Müller, D. Secondary Structure of Peptides. Polym. Bull. 1983, 10, 513-520.

(3) Deng, C.; Wu, J.; Cheng, R.; Meng, F.; Klok, H. A.; Zhong, Z. Functional Polypeptide and Hybrid Materials: Precision Synthesis via $\alpha$-Amino Acid N-Carboxyanhydride Polymerization and Emerging Biomedical Applications. Prog. Polym. Sci. 2014, 39, 330-364.

(4) Van Beek, J. D.; Beaulieu, L.; Schäfer, H.; Demura, M.; Asakura, T.; Meier, B. H. Solid-State NMR Determination of the Secondary Structure of Samia Cynthia Ricini Silk. Nature 2000, 405, 1077-1079.

(5) Vollrath, F.; Knight, D. P. Liquid Crystalline Spinning of Spider Silk. Nature 2001, 410, 541-548.

(6) Wang, Z.; Cang, Y.; Kremer, F.; Thomas, E. L.; Fytas, G. Determination of the Complete Elasticity of Nephila Pilipes Spider Silk. Biomacromolecules 2020, 21, 1179-1185.

(7) Van Beek, J. D.; Hess, S.; Vollrath, F.; Meier, B. H. The Molecular Structure of Spider Dragline Silk: Folding and Orientation of the Protein Backbone. Proc. Natl. Acad. Sci. U. S. A. 2002, 99, 10266-10271. 
(8) Huesmann, D.; Birke, A.; Klinker, K.; Türk, S.; Räder, H. J.; Barz, M. Revisiting Secondary Structures in NCA Polymerization: Influences on the Analysis of Protected Polylysines. Macromolecules 2014, 47, 928-936.

(9) Cheng, J.; Deming, T. J. Synthesis of Polypeptides by RingOpening Polymerization of $\alpha$-Amino Acid N-Carboxyanhydrides. Peptide-Based Mater. 2011, 310, 1-26.

(10) Huang, J.; Heise, A. Stimuli Responsive Synthetic Polypeptides Derived from N-Carboxyanhydride (NCA) Polymerisation. Chem. Soc. Rev. 2013, 42, 7373-7390.

(11) Klok, H. A.; Deming, T. J. Macromolecular Engineering of Polypeptides Using the Ring-Opening Polymerization of $\alpha$-Amino Acid N-Carboxyanhydrides. Macromol. Eng. Precise Synth. Mater. Prop. Appl. 2011, 1, 519-540.

(12) Kricheldorf, H. R. Polypeptides and 100 Years of Chemistry of $\alpha$-Amino Acid N-Carboxyanhydrides. Angew. Chem. Int. Ed. 2006, 45, 5752-5784.

(13) Carlsen, A.; Lecommandoux, S. Self-Assembly of PolypeptideBased Block Copolymer Amphiphiles. Curr. Opin. Colloid Interface Sci. 2009, 14, 329-339.

(14) Blout, E. R.; Idelson, M. POLYPEPTIDES. VI. POLY- $\alpha$-LGLUTAMIC ACID: PREPARATION AND HELIX-COIL CONVERSIONS 1. J. Am. Chem. Soc. 1956, 78, 497-498.

(15) Lecommandoux, S.; Achard, M. F.; Langenwalter, J. F.; Klok, H. A. Self-Assembly of Rod-Coil Diblock Oligomers Based on $\alpha$ Helical Peptides. Macromolecules 2001, 34, 9100-9111.

(16) Klok, H.-A.; Lecommandoux, S. Supramolecular Materials via Block Copolymer Self-Assembly. Adv. Mater. 2001, 13, 1217.

(17) Le Fer, G.; Wirotius, A. L.; Brûlet, A.; Garanger, E.; Lecommandoux, S. Self-Assembly of Stimuli-Responsive Biohybrid Synthetic- b-Recombinant Block Copolypeptides. Biomacromolecules 2019, 20, 254-272.

(18) Yu, M.; Nowak, A. P.; Deming, T. J.; Pochan, D. J. Methylated Mono- and Diethyleneglycol Functionalized Polylysines: Nonionic, $\alpha$ Helical, Water-Soluble Polypeptides. J. Am. Chem. Soc. 1999, 121, 12210-12211.

(19) Lu, H.; Wang, J.; Bai, Y.; Lang, J. W.; Liu, S.; Lin, Y.; Cheng, J. Ionic Polypeptides with Unusual Helical Stability. Nat. Commun. 2011, 2, 206.

(20) Baumgartner, R.; Fu, H.; Song, Z.; Lin, Y.; Cheng, J. Cooperative Polymerization of $\alpha$-Helices Induced by Macromolecular Architecture. Nat. Chem. 2017, 9, 614-622.

(21) Kramer, J. R.; Deming, T. J. Multimodal Switching of Conformation and Solubility in Homocysteine Derived Polypeptides. J. Am. Chem. Soc. 2014, 136, 5547-5550.

(22) Gharakhanian, E. G.; Deming, T. J. Chemoselective Synthesis of Functional Homocysteine Residues in Polypeptides and Peptides. Chem. Commun. 2016, 52, 5336-5339.

(23) Fu, X.; Shen, Y.; Fu, W.; Li, Z. Thermoresponsive Oligo(Ethylene Glycol) Functionalized Poly-l-Cysteine. Macromolecules 2013, 46, 3753-3760.

(24) Hwang, J.; Deming, T. J. Methylated Mono- and Di(Ethylene Glycol)-Functionalized $\beta$-Sheet Forming Polypeptides. Biomacromolecules 2001, 2, 17-21.

(25) Deming, T. J. Synthesis of Side-Chain Modified Polypeptides. Chem. Rev. 2016, 116, 786-808.

(26) Klinker, K.; Barz, M. Polypept(o)Ides: Hybrid Systems Based on Polypeptides and Polypeptoids. Macromol. Rapid Commun. 2015, 36, 1943-1957.

(27) Sanborn, T. J.; Wu, C. W.; Zuckermann, R. N.; Barron, A. E. Extreme Stability of Helices Formed by Water-Soluble Poly-NSubstituted Glycines (Polypeptoids) with $\alpha$-Chiral Side Chains. Biopolymers 2002, 63, 12-20.

(28) Mannige, R. V.; Haxton, T. K.; Proulx, C.; Robertson, E. J.; Battigelli, A.; Butterfoss, G. L.; Zuckermann, R. N.; Whitelam, S. Peptoid Nanosheets Exhibit a New Secondary-Structure Motif. Nature 2015, 526, 415-420.

(29) Weber, B.; Birke, A.; Fischer, K.; Schmidt, M.; Barz, M. Solution Properties of Polysarcosine: From Absolute and Relative
Molar Mass Determinations to Complement Activation. Macromolecules 2018, 51, 2653-2661.

(30) Barz, M.; Luxenhofer, R.; Zentel, R.; Vicent, M. J. Overcoming the PEG-Addiction: Well-Defined Alternatives to PEG, from Structure-Property Relationships to Better Defined Therapeutics. Polym. Chem. 2011, 2, 1900-1918.

(31) Fetsch, C.; Grossmann, A.; Holz, L.; Nawroth, J. F.; Luxenhofer, R. Polypeptoids from N-Substituted Glycine n-Carboxyanhydrides: Hydrophilic, Hydrophobic, and Amphiphilic Polymers with Poisson Distribution. Macromolecules 2011, 44, 6746-6758.

(32) Lau, K. H. A.; Ren, C.; Sileika, T. S.; Park, S. H.; Szleifer, I.; Messersmith, P. B. Surface-Grafted Polysarcosine as a Peptoid Antifouling Polymer Brush. Langmuir 2012, 28, 16099-16107.

(33) Nogueira, S. S.; Schlegel, A.; Maxeiner, K.; Weber, B.; Barz, M.; Schroer, M. A.; Blanchet, C. E.; Svergun, D. I.; Ramishetti, S.; Peer, D.; Langguth, P.; Sahin, U.; Haas, H. Polysarcosine-Functionalized Lipid Nanoparticles for Therapeutic mRNA Delivery. ACS Appl. Nano Mater. 2020, 3, 10634-10645.

(34) Son, K.; Ueda, M.; Taguchi, K.; Maruyama, T.; Takeoka, S.; Ito, Y. Evasion of the Accelerated Blood Clearance Phenomenon by Polysarcosine Coating of Liposomes. J. Controlled Release 2020, 322, 209-216.

(35) Melnyk, T.; Đorđević, S.; Conejos-Sánchez, I.; Vicent, M. J. Therapeutic Potential of Polypeptide-Based Conjugates: Rational Design and Analytical Tools That Can Boost Clinical Translation. Adv. Drug Delivery Rev. 2020, 160, 136-169.

(36) Birke, A.; Huesmann, D.; Kelsch, A.; Weilbächer, M.; Xie, J.; Bros, M.; Bopp, T.; Becker, C.; Landfester, K.; Barz, M. PolypeptoidBlock -Polypeptide Copolymers: Synthesis, Characterization, and Application of Amphiphilic Block Copolypept(o)Ides in Drug Formulations and Miniemulsion Techniques. Biomacromolecules 2014, 15, 548-557.

(37) Birke, A.; Ling, J.; Barz, M. Polysarcosine-Containing Copolymers: Synthesis, Characterization, Self-Assembly, and Applications. Prog. Polym. Sci. 2018, 81, 163-208.

(38) Hörtz, C.; Birke, A.; Kaps, L.; Decker, S.; Wächtersbach, E.; Fischer, K.; Schuppan, D.; Barz, M.; Schmidt, M. Cylindrical Brush Polymers with Polysarcosine Side Chains: A Novel Biocompatible Carrier for Biomedical Applications. Macromolecules 2015, 48, 20742086.

(39) Skoulas, D.; Stuettgen, V.; Gaul, R.; Cryan, S. A.; Brayden, D. J.; Heise, A. Amphiphilic Star Polypept(o)Ides as Nanomeric Vectors in Mucosal Drug Delivery. Biomacromolecules 2020, 21, 2455-2462.

(40) Schwiertz, D.; Holm, R.; Barz, M. Facile Synthesis of Amphiphilic AB3 and A3B Miktoarm PeptoMiktoStars. Polym. J. 2020, 52, 119-132.

(41) England, R. M.; Moss, J. I.; Gunnarsson, A.; Parker, J. S.; Ashford, M. B. Synthesis and Characterization of Dendrimer-Based Polysarcosine Star Polymers: Well-Defined, Versatile Platforms Designed for Drug-Delivery Applications. Biomacromolecules 2020, 21, 3332-3341.

(42) Varlas, S.; Georgiou, P. G.; Bilalis, P.; Jones, J. R.; Hadjichristidis, N.; O’Reilly, R. K. Poly(Sarcosine)-Based NanoObjects with Multi-Protease Resistance by Aqueous Photoinitiated Polymerization-Induced Self-Assembly (Photo-PISA). Biomacromolecules 2018, 19, 4453-4462.

(43) Combs, J. A.; Denicola, G. M. The Non-Essential Amino Acid Cysteine Becomes Essential for Tumor Proliferation and Survival. Cancers 2019, 11, 678.

(44) Yin, J.; Ren, W.; Yang, G.; Duan, J.; Huang, X.; Fang, R.; Li, C.; Li, T.; Yin, Y.; Hou, Y.; Kim, S. W.; Wu, G. L-Cysteine Metabolism and Its Nutritional Implications. Mol. Nutr. Food Res. 2016, 60, 134146.

(45) Sevier, C. S.; Kaiser, C. A. Formation and Transfer of Disulphide Bonds in Living Cells. Nat. Rev. Mol. Cell Biol. 2002, 3, 836-847.

(46) Schäfer, O.; Huesmann, D.; Muhl, C.; Barz, M. Rethinking Cysteine Protective Groups: S-Alkylsulfonyl-l-Cysteines for Chemo- 
selective Disulfide Formation. Chem. A Eur. J. 2016, 22, 1808518091.

(47) Schäfer, O.; Huesmann, D.; Barz, M. Poly( S -Ethylsulfonyl- 1 -Cysteines) for Chemoselective Disulfide Formation. Macromolecules 2016, 49, 8146-8153.

(48) Bauer, T. A.; Muhl, C.; Schollmeyer, D.; Barz, M. Racemic S -(Ethylsulfonyl)- Dl -cysteine N -Carboxyanhydrides Improve Chain Lengths and Monomer Conversion for B-Sheet-Controlled RingOpening Polymerization. Macromol. Rapid Commun. 2020, 2000470.

(49) Muhl, C.; Schäfer, O.; Bauer, T.; Räder, H.-J.; Barz, M. Poly( S -Ethylsulfonyl- 1 -Homocysteine): An $\alpha$-Helical Polypeptide for Chemoselective Disulfide Formation. Macromolecules 2018, 51, $8188-8196$.

(50) Klinker, K.; Schäfer, O.; Huesmann, D.; Bauer, T.; Capelôa, L.; Braun, L.; Stergiou, N.; Schinnerer, M.; Dirisala, A.; Miyata, K.; Osada, K.; Cabral, H.; Kataoka, K.; Barz, M. Secondary-StructureDriven Self-Assembly of Reactive Polypept(o)Ides: Controlling Size, Shape, and Function of Core Cross-Linked Nanostructures. Angew. Chem. Int. Ed. 2017, 56, 9608-9613.

(51) Hassan, H. M. A.; Maltman, B. A. Mixed SAMs and MALDIToF MS: Preparation of N-Glycosylamine Derivative and Thioctic Acid Methyl Ester Bearing 1,2-Dithiolane Groups and Detection of Enzymatic Reaction on Au. Bioorg. Chem. 2012, 40, 6-9.

(52) Koufaki, M.; Kiziridi, C.; Alexi, X.; Alexis, M. N. Design and Synthesis of Novel Neuroprotective 1,2-Dithiolane/Chroman Hybrids. Bioorg. Med. Chem. 2009, 17 (17), 6432-6441.

(53) Schäfer, O.; Klinker, K.; Braun, L.; Huesmann, D.; Schultze, J.; Koynov, K.; Barz, M. Combining Orthogonal Reactive Groups in Block Copolymers for Functional Nanoparticle Synthesis in a Single Step. ACS Macro Lett. 2017, 6, 1140-1145.

(54) Idelson, M.; Blout, E. R. Polypeptides. XV. 1 Infrared Spectroscopy and the Kinetics of the Synthesis of Polypeptides: Primary Amine Initiated Reactions. J. Am. Chem. Soc. 1957, 79, 39483955.

(55) Ulkoski, D.; Scholz, C. Synthesis and Application of Aurophilic Poly(Cysteine) and Poly(Cysteine)-Containing Copolymers. Polymers 2017, 9, 500.

(56) Mai, Y.; Eisenberg, A. Self-Assembly of Block Copolymers. Chem. Soc. Rev. 2012, 41, 5969-5985.

(57) Zhang, L.; Eisenberg, A. Multiple Morphologies and Characteristics of "Crew-Cut" Aggregates of Polystyrene- b -Poly(Acrylic Acid) Block Copolymers. Science 1995, 268, 1728-1731.

(58) Lund, R.; Willner, L.; Monkenbusch, M.; Panine, P.; Narayanan, T.; Colmenero, J.; Richter, D. Structural Observation and Kinetic Pathway in the Formation of Polymeric Micelles. Phys. Rev. Lett. 2009, 102, 188301.

(59) Pelton, J. T.; McLean, L. R. Spectroscopic Methods for Analysis of Protein Secondary Structure. Anal. Biochem. 2000, 277, 167-176.

(60) Hu, X.; Kaplan, D.; Cebe, P. Determining Beta-Sheet Crystallinity in Fibrous Proteins by Thermal Analysis and Infrared Spectroscopy. Macromolecules 2006, 39, 6161-6170.

(61) Goormaghtigh, E.; Ruysschaert, J. M.; Raussens, V. Evaluation of the Information Content in Infrared Spectra for Protein Secondary Structure Determination. Biophys. J. 2006, 90, 2946-2957.

(62) Greenfield, N. J. Using Circular Dichroism Spectra to Estimate Protein Secondary Structure. Nat. Protoc. 2007, 1, 2876-2890.

(63) Liu, G.; Dong, C.-M. Photoresponsive Poly( S -( o -Nitrobenzyl)- 1 -Cysteine)- b -PEO from a 1 -Cysteine $\mathrm{N}$ -Carboxyanhydride Monomer: Synthesis, Self-Assembly, and Phototriggered Drug Release. Biomacromolecules 2012, 13, 1573-1583.

(64) Jacobs, J.; Pavlović, D.; Prydderch, H.; Moradi, M. A.; Ibarboure, E.; Heuts, J. P. A.; Lecommandoux, S.; Heise, A. Polypeptide Nanoparticles Obtained from Emulsion Polymerization of Amino Acid N-Carboxyanhydrides. J. Am. Chem. Soc. 2019, 141, $12522-12526$.

(65) Fischer, K.; Schmidt, M. Pitfalls and Novel Applications of Particle Sizing by Dynamic Light Scattering. Biomaterials 2016, 98, 79-91.
(66) Zhang, L.; Eisenberg, A. Thermodynamic vs Kinetic Aspects in the Formation and Morphological Transitions of Crew-Cut Aggregates Produced by Self-Assembly of Polystyrene-b-Poly(Acrylic Acid) Block Copolymers in Dilute Solution. Macromolecules 1999, 32, 2239-2249.

(67) Zhang, L.; Shen, H.; Eisenberg, A. Phase Separation Behavior and Crew-Cut Micelle Formation of Polystyrene-b-Poly(Acrylic Acid) Copolymers in Solutions. Macromolecules 1997, 30, 1001-1011.

(68) Gilroy, J. B.; Gädt, T.; Whittell, G. R.; Chabanne, L.; Mitchels, J. M.; Richardson, R. M.; Winnik, M. A.; Manners, I. Monodisperse Cylindrical Micelles by Crystallization-Driven Living Self-Assembly. Nat. Chem. 2010, 2, 566-570.

(69) Kelley, E. G.; Murphy, R. P.; Seppala, J. E.; Smart, T. P.; Hann, S. D.; Sullivan, M. O.; Epps, T. H. Size Evolution of Highly Amphiphilic Macromolecular Solution Assemblies via a Distinct Bimodal Pathway. Nat. Commun. 2014, 5, 3599.

(70) Mochida, Y.; Cabral, H.; Miura, Y.; Albertini, F.; Fukushima, S.; Osada, K.; Nishiyama, N.; Kataoka, K. Bundled Assembly of Helical Nanostructures in Polymeric Micelles Loaded with Platinum Drugs Enhancing Therapeutic Efficiency against Pancreatic Tumor. ACS Nano 2014, 8, 6724-6738. 